\title{
Impact Toughness and Ductility Enhancement of Biodegradable Poly(lactic acid)/Poly( $\varepsilon$-caprolactone) Blends via Addition of Glycidyl Methacrylate
}

\author{
Wei Kit Chee, ${ }^{1}$ Nor Azowa Ibrahim, ${ }^{1}$ Norhazlin Zainuddin, \\ Mohd Faizal Abd Rahman, ${ }^{2}$ and Buong Woei Chieng ${ }^{1}$ \\ ${ }^{1}$ Chemistry Department, Universiti Putra Malaysia, 43400 Serdang, Selangor, Malaysia \\ ${ }^{2}$ Radiation Processing Technology Department, Malaysia Nuclear Agency, Bangi, 43000 Kajang, Selangor, Malaysia \\ Correspondence should be addressed to Nor Azowa Ibrahim; norazowa@science.upm.edu.my
}

Received 9 April 2013; Revised 11 June 2013; Accepted 11 June 2013

Academic Editor: Wen-Hua Sun

Copyright (c) 2013 Wei Kit Chee et al. This is an open access article distributed under the Creative Commons Attribution License, which permits unrestricted use, distribution, and reproduction in any medium, provided the original work is properly cited.

Poly(lactic acid) (PLA)/poly( $\varepsilon$-caprolactone) (PCL) blends were prepared via melt blending technique. Glycidyl methacrylate (GMA) was added as reactive compatibilizer to improve the interfacial adhesion between immiscible phases of PLA and PCL matrices. Tensile test revealed that optimum in elongation at break of approximately $327 \%$ achieved when GMA loading was up to $3 \mathrm{wt} \%$. Slight drop in tensile strength and tensile modulus at optimum ratio suggested that the blends were tuned to be deformable. Flexural studies showed slight drop in flexural strength and modulus when GMA wt\% increases as a result of improved flexibility by finer dispersion of PCL in PLA matrix. Besides, incorporation of GMA in the blends remarkably improved the impact strength. Highest impact strength was achieved (160\% compared to pure PLA/PCL blend) when GMA loading was up to 3 wt $\%$. SEM analysis revealed improved interfacial adhesion between PLA/PCL blends in the presence of GMA. Finer dispersion and smooth surface of the specimens were noted as GMA loading increases, indicating that addition of GMA eventually improved the interfacial compatibility of the nonmiscible blend.

\section{Introduction}

Over decades, the extreme usage of nonbiodegradable polyolefin-based plastics had raised numerous environmental problems including reproducibility and wastes generation as well, subsequently causing increased volume of commercial and industrial dumps in the landfills [1]. Although many solutions have been proposed for management of plastic waste including recycling, landfill disposal, and waste incineration, but none of these have made a significant impact towards the environmental issues caused by the nonbiodegradable plastics. Recycling of plastics has not been a major choice because recycled products will not have good quality due to natural characteristics of plastic. Incineration of plastics will eventually release toxic gases and vapors which are proven to be serious health threats [2]. Dumping of plastics in landfill will be the least chosen due to space limitations. This phenomenon induces the development towards biodegradable polymers which are produced from fully renewable resources such as feed stocks and plants. Biodegradable polymers yet receive high attention due to the major advantage of being fully-biodegradable into simple organic substances of carbon, hydrogen and oxygen by interactions with microorganisms such as bacteria, algae, and fungi, upon disposal on bioactive environments. Poly(lactic acid) (PLA) is a linear polyester produced from renewable resources primarily corn starch and sugar canes [3]. The monomer, lactic acid is a compound that plays a significant role in several biochemical processes. It is mainly prepared by the bacterial fermentation of carbohydrates. The promising characteristics of PLA are good mechanical properties, thermal stability, process ability, and low environment impact by being fully biodegradable [4]

Momentarily, large-scale usage of PLA in industrial applications was mainly of films and container for packaging, pharmaceutical as well as medical usage. Increase in demands of biodegradable plastics in designing materials for green 
environment opens up a new market in which PLA promises high potential in commercial usages. However, the brittleness characteristics as well as its high glass transition temperature at around $60^{\circ} \mathrm{C}$ render it to be hard and stiff at room temperature. These limit PLA application in various fields [5]; thus there is a need of modifying the stiff backbone chain of polylactides.

Modification of PLA has been carried out by many researchers including grafting, polymer blending, and addition of plasticizer [6]. Chemical and radiation grafting was more commonly done due to the ease of being carried out and steps wise process. Hassouna et al. [7] studied a new way of plasticizing polylactide with anhydride-grafted PLA (MAG-PLA) copolymer. Addition of the copolymer significantly lowers the glass transition temperature of the blends. Besides, molecular weight of PLA does not drop dramatically by thermal degradation upon addition of MAGPLA. In another study by $\mathrm{Su}$ et al., glycidyl methacrylate grafted poly(ethylene-octane) (mPOE) were prepared by chemical grafting method. PLA matrix was molten mixed with mPOE with increasing content of mPOE from 10, 15, and 30 up to $45 \mathrm{wt} \%$, respectively, and it has been claimed that glass transition peaks of PLA and $\mathrm{mPOE}$ approach closer to each other as $\mathrm{mPOE}$ content increased, indicating enhanced compatibility. Besides, significant improvement was noted on the elongation at break and impact strength of the blend [8]. Polylactide grafted with maleic anhydride-functionalized poly(ethylene-octene) copolymer (TPO-PLA) via free radical reaction was reported successfully reducing the interfacial tension between the immiscible polymers.

PLA is also melt-blended with two or more polyesters at which an improvement has been reported in mechanical properties of virgin PLA matrix [3]. However, the polymer blends often consist of nonmiscible two-phase system, at which the mechanical and thermal properties of the main matrix still retained the most within the blend itself, whereas the extent of modification of the blend solely depends on the amount of the second component being blended as well as the extent of compatibilization between the two phases. Particularly, the second component usually comprises of elastomeric polymers with superb flexibility such as PCL, PBAT, or PBS in expect to improve the toughness performance of PLA matrix as being reported in several literatures [911]. An often successful approach to modify or toughen the brittle polymers is via blending of elastomeric components at which poly( $\varepsilon$-caprolactone) (PCL) is one of the most promising choices [12]. PCL exhibited low glass transition temperature, semi crystalline and retained high flexibility at room temperature. Besides, it is nontoxic therefore suitable for applications in various fields. PCL is highly elastomeric and tough but exhibited much lower magnitude of modulus compared to PLA. In order to be applicable and useful the material properties must be tuned to fulfill the engineering met [10]. Blending of PCL in brittle PLA matrix is expected to improve toughness performance of PLA. Particularly, blending of PLA/PCL has been reported to improve in flexibility and ductility of the blends by various authors [2, $10,13]$. However, it was proven by the authors that the two biodegradable polymers are immiscible, thus deteriorating other mechanical properties.

In current investigation, various compositions of poly(lactic acid) (PLA)/poly( $\varepsilon$-caprolactone) (PCL) were prepared by melt blending technique. Glycidyl methacrylate is introduced as a compatibilizing agent into the polymer matrices to improve the compatibility as well as interfacial adhesion. The effects of the amount of GMA on mechanical properties have been investigated.

\section{Experimental}

2.1. Materials. Poly(lactic acid) (PLA grade: 4060D) (polyD/L-lactide or PDLLA) was purchased from Nature Works LLC, USA. The resin was provided in the form of pellets with approximately $11 \%$ to $13 \%$ of D-lactide content. Poly( $\varepsilon$-caprolactone) was obtained from Solvay Caprolactone, Warrington, England. Glycidyl methacrylate (GMA) was obtained from Sigma-Aldrich, WI, USA. The physical properties of polyesters and compatibilizing agent used in this study was summarized in Table 1. PLA pellets were subjected to preheating at $60^{\circ} \mathrm{C}$ for 24 hours in drying oven before melt blending in order to remove moisture.

2.2. Melt Blending. PLA/PCL blends were prepared at various compositions $(90: 10,85: 15,80: 20,75: 25$, and $70: 30)$. The blending was carried out using a $30 \mathrm{~g}$ capacity twin screw melt mixer (Brabender GmbH, Duisburg, Germany) with rotary speed of $50 \mathrm{rpm}$ and the temperature was set at $170^{\circ} \mathrm{C}$ for 10-minute duration. Reactive compatibilizer, GMA were premixed with fixed ratio of PLA/PCL $(85: 15)$ to prepare PLA/PCL/GMA blends, respectively. Weight content of GMA was varied from 1 to $5 \mathrm{wt} \%$ according to the total mass of melt mixer capacity.

2.3. Specimens Preparation. Molded sheets with dimension of $0.1 \mathrm{~cm} \times 15 \mathrm{~cm} \times 15 \mathrm{~cm}$ of the virgin PLA matrix, PLA/PCL blend, and PLA/PCL/GMA blends were prepared using a hotpress (Hsin-Chi Machinery Co. Ltd) with upper and lower pressure of $110 \mathrm{~kg} / \mathrm{cm}^{2}$ and a cycle time of 10 minutes. The cooling duration was set for 5 minutes. Tensile test specimens were prepared from the sheets using a Dumbbell cutter as in ASTM D638-V standard. Flexural test specimens were prepared from the sheets with dimension of $0.3 \mathrm{~cm} \times 15 \mathrm{~cm} \times$ $15 \mathrm{~cm}$ according to ASTM D790, whereas Izod impact test specimens were prepared according to ASTM D256.

\section{Tests and Characterization}

3.1. Mechanical Test. The prepared test specimens of virgin PLA and blends were kept in sealed desiccators for $48 \mathrm{~h}$ prior to mechanical test. Tensile strength, elongation at break, and tensile modulus of the specimens were tested using INSTRON (MODEL: 4032) mechanical tester. 5 replicate specimens were subjected to the test and the average of these data was reported. The standard deviation of the corresponding experimental data was also indicated as error bars. Specimen in dumbbell shape according to ASTM D638 
TABLE 1: Summary of physical properties of polyesters and compatibilizing agent.

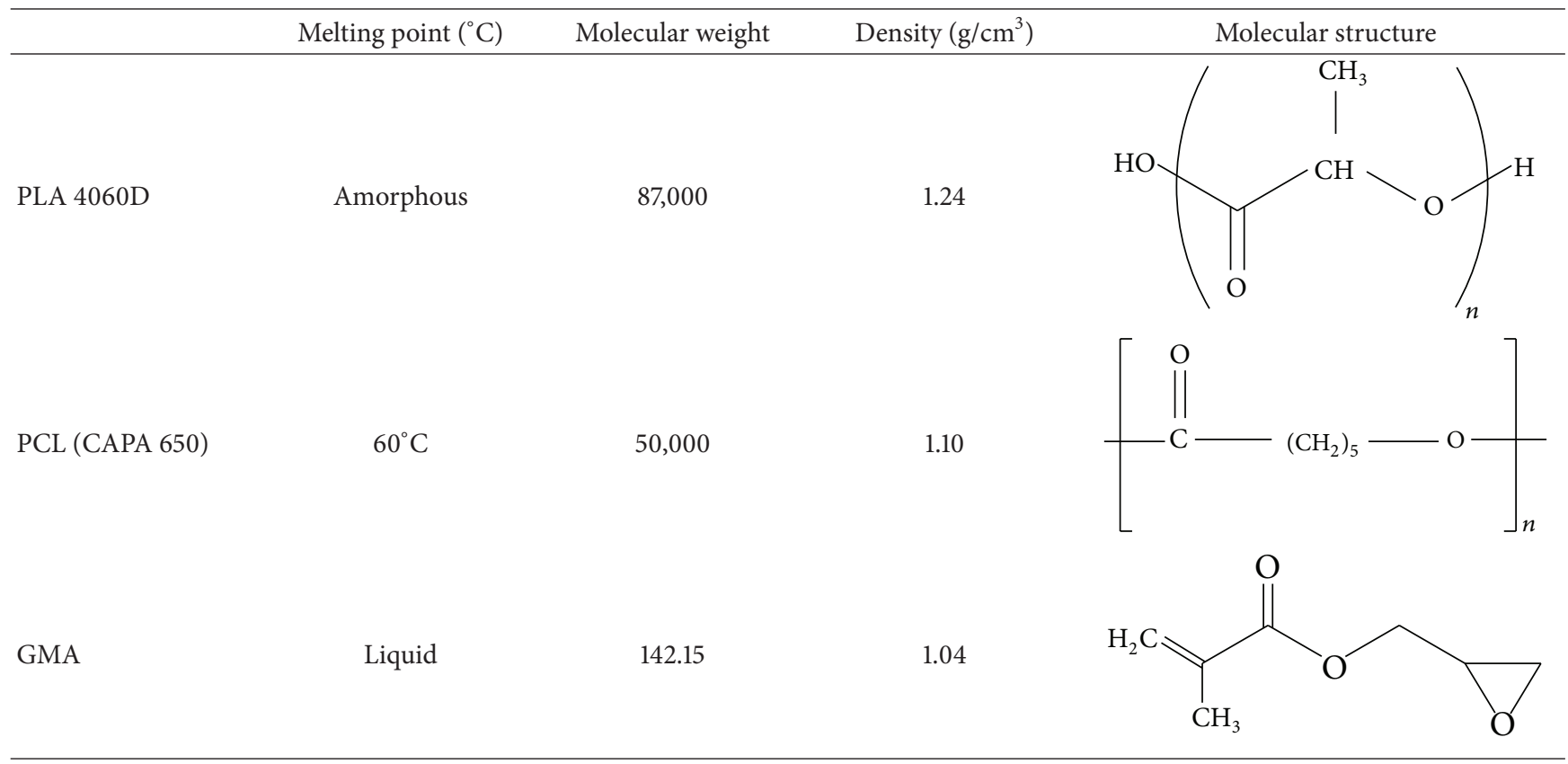

$\mathrm{V}$ type was strained at cross-head speed of $10 \mathrm{~mm} / \mathrm{min}$ and gauge load of $1.0 \mathrm{kN}$. Flexural test was done using INSTRON (MODEL: 4032) according to ASTM D790. Unnotched Izod impact test was carried out using Izod Impact Tester (International Equipments, Mumbai, India).

\subsection{Morphological Properties}

3.2.1. Scanning Electron Microscopy (SEM). Fracture surface morphology of prepared PLA/PCL blend and PLA/ PCL/GMA blends was studied using a scanning electron microscopy (SEM JEOL). The facture surface of specimens was gold-coated prior to analysis in order to avoid electrostatic charging during the microscopy test.

\subsection{Spectroscopy Analysis}

3.3.1. Fourier Transformation Infrared Spectroscopy (FT-IR). FT-IR spectra for virgin PLA, PCL, and prepared blends were recorded over the range of (400-4000) $\mathrm{cm}^{-1}$ using Spectrum BX Perkin Elmer using Attenuated Total Reflectance (ATR) method.

\section{Results and Discussion}

\subsection{Mechanical Properties}

4.1.1. Tensile Test. The mechanical properties including tensile strength, elongation at break, and tensile modulus of virgin PLA, PCL, and PLA/PCL blends were illustrated in Table 2. As reported by various authors, virgin PLA exhibits very high tensile strength $(51.38 \mathrm{MPa})$ and tensile modulus.
However, relatively low elongation at break suggested that virgin PLA matrix is very brittle and not mechanically feasible. Being elastomeric, PCL exhibits a very high elongation at break of $1996.00 \%$ and a relatively much lower tensile modulus of 220.10 MPa. Thus, it was chosen as the blending target for tuning rigid PLA matrix to ductile. PCL was blended with PLA in the weight percentage of $10 \%, 15 \%, 20 \%, 25 \%$, and $30 \%$ respectively. Notice that the tensile strength decreased from 47.31 to $32.39 \mathrm{MPa}$ and tensile modulus decreased from 1066.75 to $881.15 \mathrm{MPa}$ as the PCL content increased from 10 to $30 \mathrm{wt} \%$. This is most probably due to the presence of PCL in PLA matrix which reduced the crystalline behavior of pure matrix, and there was very little mixing between PLA and PCL in the blend [10]. PLA/PCL blend with the ratio of $75: 25$ exhibited highest elongation at break compared to other blend ratios, which may due to the introduction of elastomeric PCL into PLA matrix given certain flexibility in the blend. When the ratio of PCL exceeded $30 \mathrm{wt} \%$, phase separation occurred and poor interfacial adhesion between the polymers resulted in a drop in elongation at break [1]. This result is further confirmed by the literature [14]. As reported, tensile strength of PLA/PCL blend decreased from 55.9 to 27.1 MPa as PCL content increased from 0 to $50 \mathrm{wt} \%$; however its elongation at break increases from 4.9 to $379.3 \%$.

Specimen of $90: 10$ ratio exhibited slightly higher elongation than that of PLA85/PCL15 specimen; however high tensile modulus suggested that the specimen was stiff. Besides that, specimen with $80: 20$ ratio recorded higher elongation with low modulus; however incorporation of more PCL content was needed which will be very costly. Further increment of PCL content up to $25 \mathrm{wt} \%$ resulted in drastic improvement in elongation at break with moderate tensile strength achieved but not cost effective due to additional 
TABLE 2: Tensile properties of pure PLA, PCL and PLA/PCL blends.

\begin{tabular}{lccc}
\hline PLA/PCL ratio & Tensile strength $(\mathrm{MPa})$ & Elongation at break (\%) & Tensile modulus $(\mathrm{MPa})$ \\
\hline $100 / 0$ & $51.38 \pm 1.19$ & $6.64 \pm 0.46$ & $1085.60 \pm 37.19$ \\
$0 / 100$ & $40.60 \pm 3.06$ & $1996.00 \pm 221.00$ & $220.10 \pm 5.20$ \\
$90 / 10$ & $47.31 \pm 1.57$ & $19.24 \pm 0.69$ & $1066.75 \pm 14.64$ \\
$85 / 15$ & $42.88 \pm 1.57$ & $17.06 \pm 3.39$ & $949.00 \pm 37.47$ \\
$80 / 20$ & $41.52 \pm 1.30$ & $26.60 \pm 1.69$ & $995.80 \pm 19.07$ \\
$75 / 25$ & $39.91 \pm 1.68$ & $46.60 \pm 2.96$ & $980.20 \pm 24.13$ \\
$70 / 30$ & $32.39 \pm 1.27$ & $27.84 \pm 0.65$ & $881.15 \pm 21.36$ \\
\hline
\end{tabular}

amount of PCL were needed. Thus, $85: 15$ ratio was retained to fabricate blends in the presence of GMA mainly of the considerable high tensile strength as well as moderate elongation at break.

Tensile strength, elongation at break, and tensile modulus of PLA/PCL/GMA blends were shown in Figures 1, 2, and 3. It was evident that PLA/PCL (85/15) blend exhibited improved tensile strength $(42.9$ to $46.7 \mathrm{MPa})$ when the content of GMA exceeds $1.0 \mathrm{wt} \%$, suggesting that the addition of $1 \mathrm{wt} \%$ GMA eventually improved the tensile strength of PLA/PCL matrices. However, notice that tensile strength decreased gradually as GMA content increased which may be due to improved compatibilization that resulted more drastic character of PCL was imparted on PLA. This result agreed with that of Harada et al. [15] who reported that addition of DCP as compatibilizer resulted in gradual decrease in tensile strength of PLA/PBS blends. On the other hand, elongation at breaks increased as GMA was introduced and the highest elongation of $327.70 \%$ was achieved at $3.0 \mathrm{wt} \%$, suggesting that compatibilization effect eventually took place between PLA and PCL components upon addition of GMA and the outcome was most efficient at $3 \mathrm{wt} \%$ of GMA. However as the compatibilizer content exceeded optimum value, adverse effects occur on the elongation, probably due to the excess of GMA which was immiscible with PLA/PCL matrices and thus resulted in phase separation. This result agreed with the study of [16], where the ultimate strain of PLA/PBAT blend increased when T-GMA content increased but then dropped when beyond the optimum point of $5 \mathrm{wt} \%$. Tensile modulus of the blends decreased slightly from $949.0 \mathrm{MPa}$ to $901.8 \mathrm{MPa}$ when GMA loading increases up to $3 \mathrm{wt} \%$, suggesting that the specimen was tuned to stretchable. This finding complied with the result of elongation where the highest value was achieved at $3 \mathrm{wt} \%$ of GMA. The increase in compatibility between virgin PLA matrix and PCL phase as well as improvement of interfacial adhesion resulted in highly stretchable nature of PCL was successfully imparted onto PLA matrix. This was evident by large increment of elongation at break and lower tensile modulus recorded suggesting that specimens were tuned highly deformable. The reactions most probably took place between the epoxy group of GMA and hydrolyzed carboxyl or hydroxyl groups at the terminal of polymeric chains thus improving the interfacial adhesion between PLA and PCL components. This finding was also in accordance with the study in the literature [8] where the

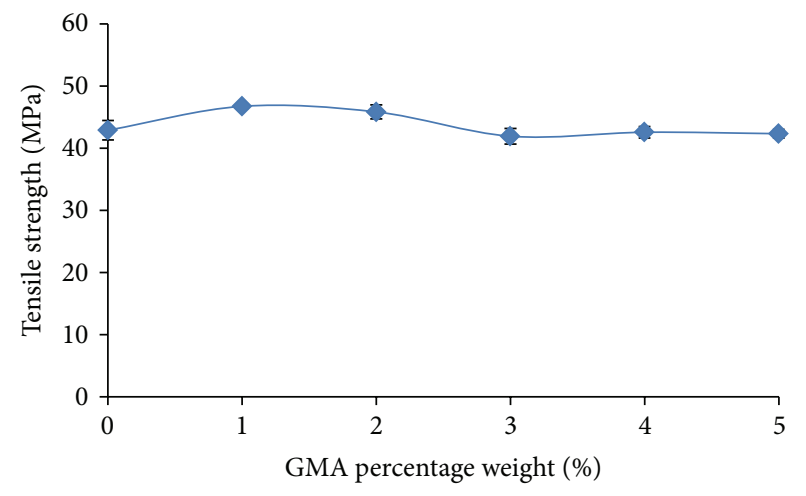

Figure 1: Tensile strength of PLA/PCL/GMA blends.

elongation at break and impact strength of PLA/POE blend were increased when weight percentage of GMA-grafted POE increased. The author explained that the reaction took place between the epoxy groups of the mPOE and PLA, resulting in surface tension and interface energy which were lessened, thus strengthening the interfacial adhesion between PLA and mPOE phases.

4.1.2. Flexural Test. The flexural test of pure PLA, PLA85/PCL15, and PLA85/PCL15/GMA blends was shown in Figures 4 and 5. The brittleness characteristic of neat PLA was shown by high value of flexural strength and modulus, indicating that the specimen was stiff and rigid. Figure 4 revealed that the flexural strength of pure PLA/PCL blend dropped from $62.01 \mathrm{MPa}$ to $47.87 \mathrm{MPa}$ as GMA content increased from 0 to $5 \mathrm{wt} \%$. Increasing content of GMA resulted in decreasing the stiffness of PLA/PCL blend.

Similarly, flexural modulus of the blends dropped gradually from $2980.5 \mathrm{MPa}$ to $2415.0 \mathrm{MPa}$ when increasing GMA content from 0 to $5 \mathrm{wt} \%$. This may be due to the fact that epoxy group of GMA could react with the hydrolyzed carboxylic or hydroxyl groups upon high temperature treatment of PLA and PCL, therefore improving the interfacial adhesion of PLA/PCL blends. Note that PCL has elastomeric properties, thus contributing ductile behavior towards the PLA matrix. This may have contributed toward decreasing flexural strength and flexural modulus of PLA/PCL blend. A decrease in flexural strength and flexural modulus showed 


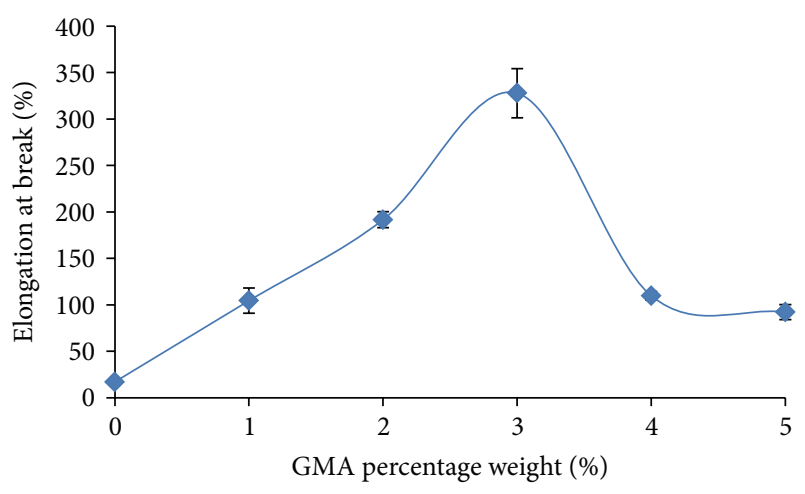

FIGURE 2: Elongation at break of PLA/PCL/GMA blends.

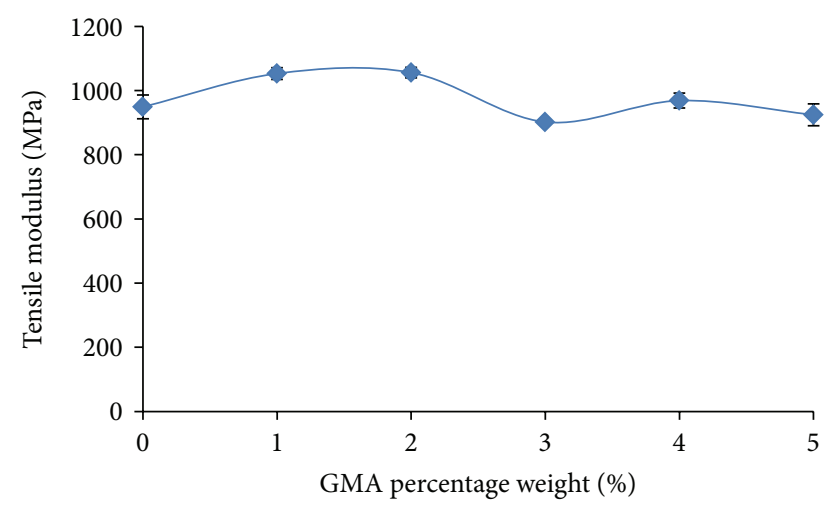

Figure 3: Tensile mModulus of PLA/PCL/GMA blends.

that the force needed to bend the specimen was lower, indicating that the specimen was more flexible. Supporting findings were reported by $\mathrm{Xu}$ et al. [17] where GMA was grafted onto PLA polymer chains (PLA-GMA) and added in PLA/Bamboo flour (BF) biocomposites as compatibilizer. As claimed there was an increment in flexural strength and flexural modulus when PLA-GMA content increased, probably because the epoxy group of PLA-GMA reacted with hydroxyl groups in cellulose of BF, whereas PLA-GMA has good compatibility with PLA matrix; thus interfacial adhesion of PLA/BF composites is improved. BF was added as filler, and therefore improved compatibility of PLA and BF resulted in stronger and stiffer biocomposites.

4.1.3. Izod Impact Test. Figure 6 shows the unnotched Izod impact test as the function of GMA loading on PLA/PCL blends. The impact strength of virgin PLA is relatively low $(235.83 \mathrm{~J} / \mathrm{m})$. This finding confirmed the brittle characteristic and low impact strength of PLA. There is a dramatic increment of impact strength when PCL was blended into PLA matrix, indicating that the introduction of PCL tunes the brittle PLA into ductile $(418.36 \mathrm{~J} / \mathrm{m})$. As the GMA loading increases from $0.5 \%$ up to $3.0 \%$, a significant increase in impact strength of the samples was recorded from $477.68 \mathrm{~J} / \mathrm{m}$ up to $811.12 \mathrm{~J} / \mathrm{m}$ (170\%), respectively. Further increment of GMA loading resulted in a drop in impact strength of the blends which may be due to the excess of immiscible GMA in

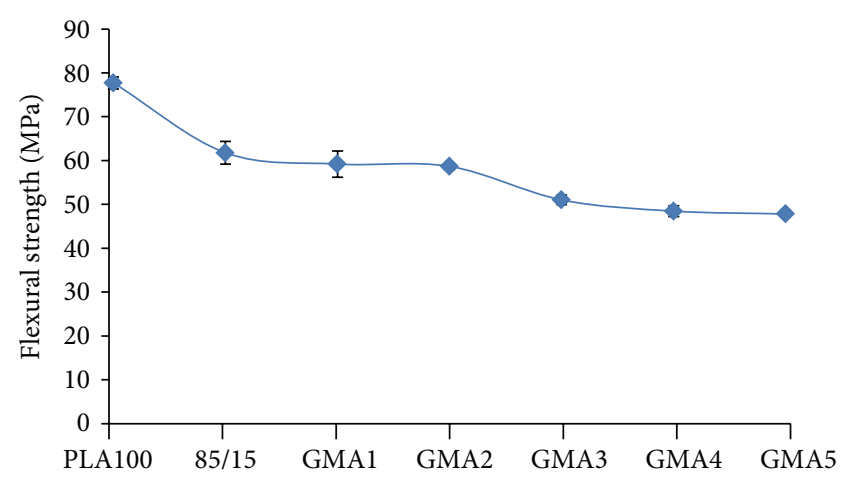

FIgURE 4: Flexural strength of pure PLA, PLA85/PCL15, and GMA blends.

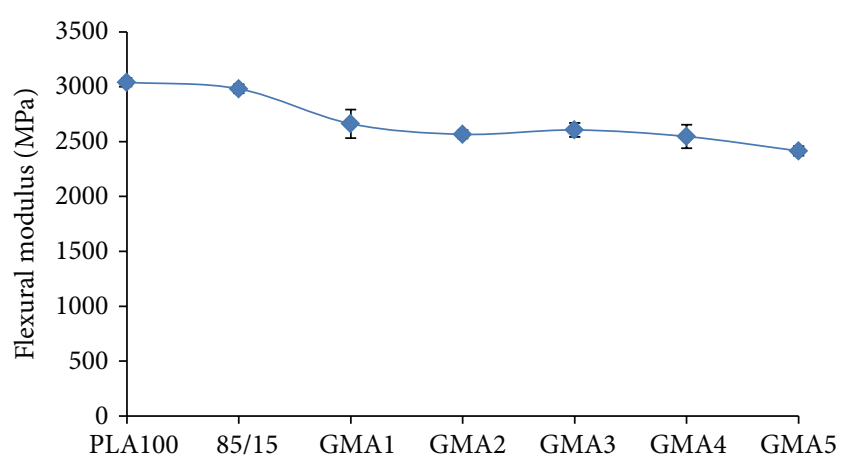

FIgure 5: Flexural modulus of pure PLA, PLA85/PCL15, and GMA blends.

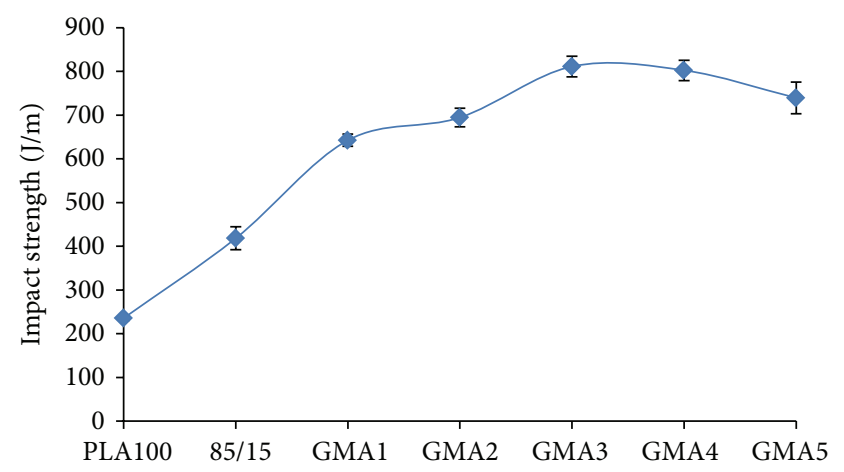

FIGURE 6: Effect of GMA on impact strength of PLA/PCL blends.

PLA/PCL matrix, causing phase separation and thus affecting the toughness properties of prepared blends.

\subsection{Morphology Properties}

4.2.1. Fourier Transform Infrared Analysis (FT-IR). Figure 7(a) shows FT-IR analysis of virgin PLA, PCL, and PLA/PCL 


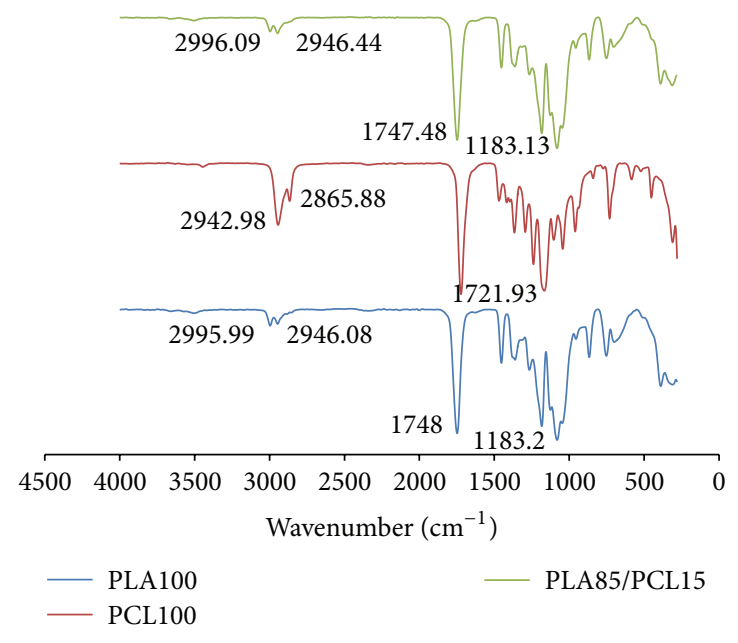

(a)

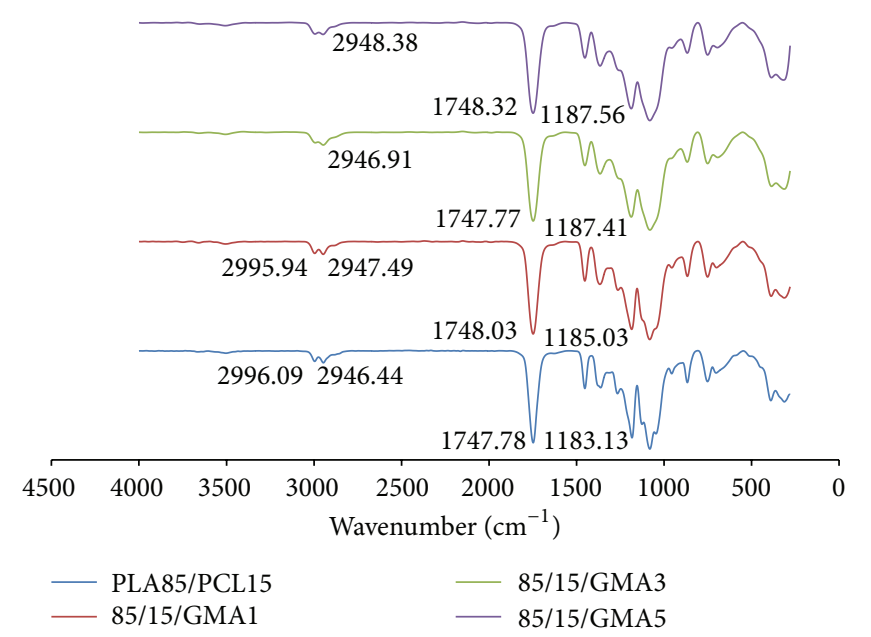

(b)

FIGURE 7: (a) FT-IR spectra of pure PLA, PCL and PLA/PCL ( 85 : 15) blend. (b) FT-IR spectra of PLA/PCL/GMA blends.

blends. Notice that there are a few characteristic peaks of virgin PLA matrix as well as PCL in the blends. Peaks located at $2995.99 \mathrm{~cm}^{-1}, 2946.08 \mathrm{~cm}^{-1}$ for virgin PLA and $2942.98 \mathrm{~cm}^{-1}, 2865.88 \mathrm{~cm}^{-1}$ for PCL were responsible for the stretching vibration of $-\mathrm{CH}_{2}$ whereas peaks located at $1748.00 \mathrm{~cm}^{-1}$ for PLA and $1721.93 \mathrm{~cm}^{-1}$ for PCL were assigned to the vibration of $-\mathrm{C}=\mathrm{O}$ bonds, respectively. Besides, peak recorded at $1183.20 \mathrm{~cm}^{-1}$ was responsible for stretching vibration of C-O of PLA. For the blend, the characteristic peaks of PLA were noticed at $2996.09 \mathrm{~cm}^{-1}, 2946.44 \mathrm{~cm}^{-1}$, and $1747.48 \mathrm{~cm}^{-1}$, respectively. C-O stretching vibration was also noticed at $1183.13 \mathrm{~cm}^{-1}$ [18]. No significant shift in wavenumber was detected for the blend, suggesting that little or no interactions occurred within PLA and PCL components upon blending. Peaks for PCL were hardly noticed due to minor content of PCL (PLA/PCL ratio: 85/15) in the blend.

Figure 7(b) represents FT-IR spectra of PLA85/PCL15 blend and PLA/PCL/GMA blends. For blends with GMA content from 1,3 , and $5 \mathrm{wt} \%$, the spectrum shows the peaks at $2947.4944 \mathrm{~cm}^{-1}, 2946.9144 \mathrm{~cm}^{-1}$, and $2948.3844 \mathrm{~cm}^{-1}$ which are due to $\mathrm{C}-\mathrm{H}$ stretching. Stretching vibration for $\mathrm{C}=\mathrm{O}$ remained nearly unchanged upon addition of GMA which could be observed at $1748.0344 \mathrm{~cm}^{-1}, 1747.7744 \mathrm{~cm}^{-1}$, and $1748.3244 \mathrm{~cm}^{-1}$, respectively, which explained that no reaction occurred on $\mathrm{C}=\mathrm{O}$ bonds of PLA backbone chains. $\mathrm{C}-$ O bond stretching vibration for PLA85/PCL15 blend was noticed at $1183.13 \mathrm{~cm}^{-1}$. However, the value shifted to a higher wavelength of $1185.0344 \mathrm{~cm}^{-1}, 1187.4144 \mathrm{~cm}^{-1}$, and $1187.564 \mathrm{~cm}^{-1}$, respectively, as the GMA content in specimens increased from 1 to $5 \mathrm{wt} \%$. This indicated that reactions eventually occurred at hydroxyl groups at the terminal of PLA polymeric chains which resulted in the shifting of $\mathrm{C}-\mathrm{O}$ stretching vibration.

4.2.2. SEM Morphology Analysis. Scanning electron microscopy (SEM) was applied to observe the tensile fracture surface directly in microstructure scale of PLA/PCL blend
(Figures 8(a) and 8(b)), and GMA compatibilized blends (Figure $7 \mathrm{c}$-h).

From Figures $8(a)$ and $8(b)$, the fracture surface of PLA/PCL matrices could be evaluated. It can be seen that the ductile nature of PCL is brought into the brittle PLA matrix with random and fibrous structure [14]. As the weight percentage of GMA increases from 1 to $3 \mathrm{wt} \%$ (Figures 8(c)$8(f)$ ), it can be observed that the fracture surface of the samples was tuned to be smoother and more uniform. The random and fibrous structure of 85/15 blend was tuned into a finer dispersion morphology, showing better compatibility of PCL as dispersed phase in PLA matrix. This indicated that GMA effectively acts as reactive compatibilizer at the interface of PLA and PCL as expected. Similar findings were claimed in the literature [1] where the author stated that in the presence of GMA, the blends of PLA and PBAT showed a better miscibility and more shear yielding upon fracture. However when $5 \mathrm{wt} \%$ of GMA are added (Figures $8(\mathrm{~g})$ and $8(\mathrm{~h}))$, it can be seen that small tiny nodes which are embedded on PLA/PCL blend matrix are observed, which can be clearly seen on 1000x magnification (Figure $8(\mathrm{~h})$ ). The nodes seem to be in the GMA phase which in excess, due to immiscibility between GMA and PLA matrices. Similar result was also recorded by author [19], where PE-GMA phase was found as the nodes in LDPE matrix due to immiscibility between PE-GMA and LDPE matrices.

\section{Conclusion}

PLA/PCL/GMA blends were prepared using melt mixing technique. The influence of GMA on mechanical and morphological properties of the blends has been studied. Addition of GMA as compatibilizing agent has remarkably enhanced the elongation and impact toughness of the blends at $3 \mathrm{wt} \%$. Flexural strength and flexural modulus drop as GMA loading increases, indicating the specimens were successfully tuned to be ductile and deformable. SEM analysis of fracture surface of specimens revealed that a finer and smooth dispersion was observed as GMA loading increases up to 


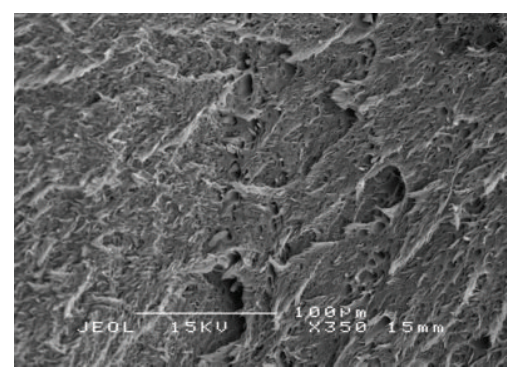

(a)

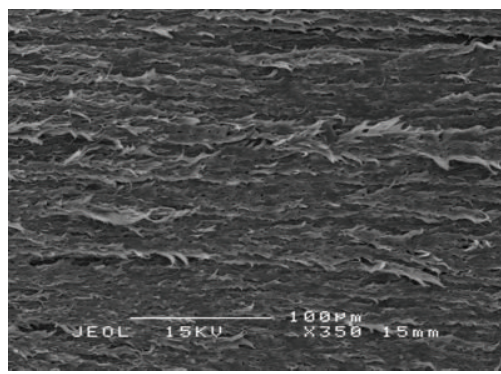

(c)

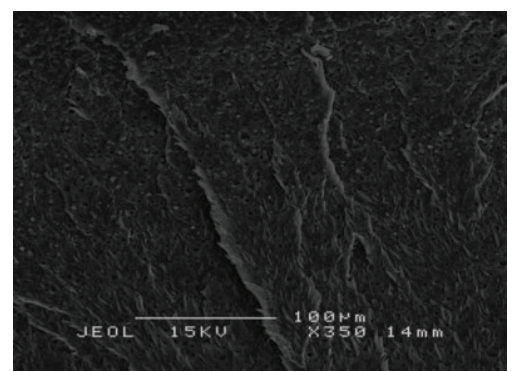

(e)

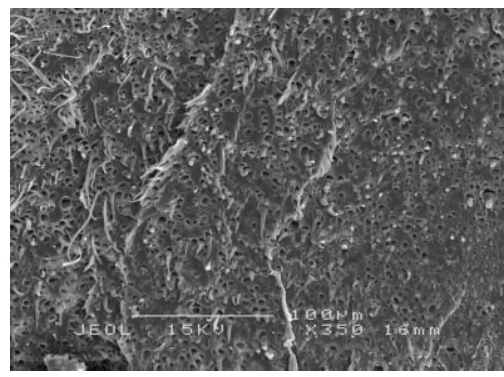

(g)

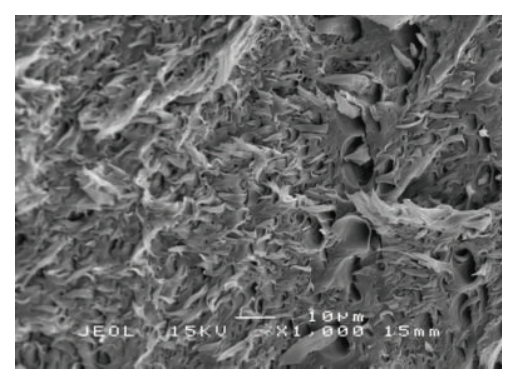

(b)

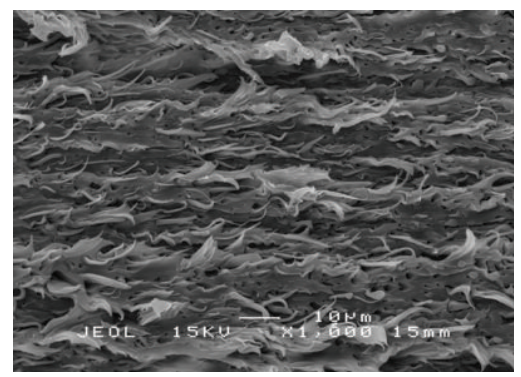

(d)

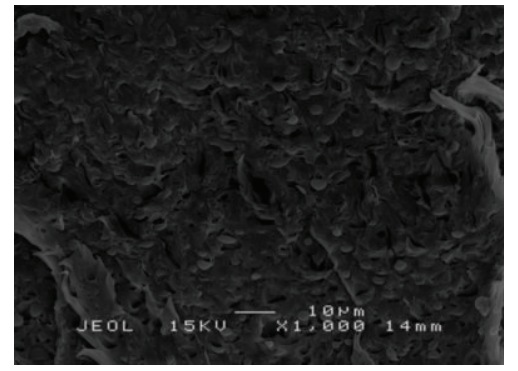

(f)

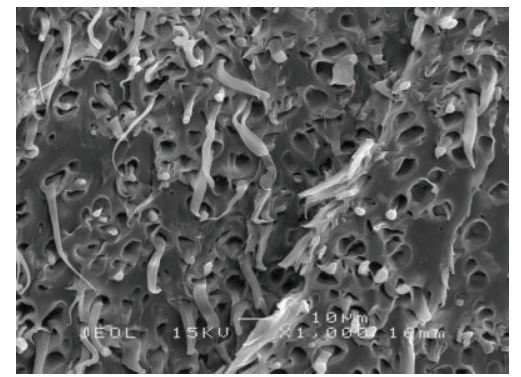

(h)

Figure 8: ((a)-(h)) SEM micrograph of PLA/PCL blends at GMA wt\% of 0.0 ((a) and (b)) 1.0 ((c) and (d)) $3.0((\mathrm{e})$ and (f)) and $5.0((\mathrm{~g})$ and (h)) at different magnifications ((a), (c), (e), and (g)) 0.3kx, ((b), (d), (f), and (h)) 1.0kx.

$3 \mathrm{wt} \%$, which indicates that a better compatibility is achieved between the interfaces of nonmiscible PLA/PCL matrices.

\section{References}

[1] M. Kumar, S. Mohanty, S. K. Nayak, and M. Rahail Parvaiz, "Effect of glycidyl methacrylate (GMA) on the thermal, mechanical and morphological property of biodegradable PLA/ PBAT blend and its nanocomposites," Bioresource Technology, vol. 101, no. 21, pp. 8406-8415, 2010.

[2] C. L. Simões, J. C. Viana, and A. M. Cunha, "Mechanical properties of $\operatorname{poly}(\varepsilon$-caprolactone) and poly(lactic acid) blends,"
Journal of Applied Polymer Science, vol. 112, no. 1, pp. 345-352, 2009.

[3] O. Martin and L. Avérous, "Poly(lactic acid): plasticization and properties of biodegradable multiphase systems," Polymer, vol. 42, no. 14, pp. 6209-6219, 2001.

[4] L.-T. Lim, R. Auras, and M. Rubino, "Processing technologies for poly(lactic acid)," Progress in Polymer Science (Oxford), vol. 33, no. 8, pp. 820-852, 2008.

[5] K. Madhavan Nampoothiri, N. R. Nair, and R. P. John, "An overview of the recent developments in polylactide (PLA) research," Bioresource Technology, vol.101, no. 22, pp. 8493-8501, 2010. 
[6] C.-H. Ho, C.-H. Wang, C.-I. Lin, and Y.-D. Lee, "Synthesis and characterization of TPO-PLA copolymer and its behavior as compatibilizer for PLA/TPO blends," Polymer, vol. 49, no. 18, pp. 3902-3910, 2008.

[7] F. Hassouna, J.-M. Raquez, F. Addiego, P. Dubois, V. Toniazzo, and D. Ruch, "New approach on the development of plasticized polylactide (PLA): grafting of poly(ethylene glycol) (PEG) via reactive extrusion," European Polymer Journal, vol. 47, no. 11, pp. 2134-2144, 2011.

[8] Z. Su, Q. Li, Y. Liu, G.-H. Hu, and C. Wu, "Compatibility and phase structure of binary blends of poly(lactic acid) and glycidyl methacrylate grafted poly(ethylene octane)," European Polymer Journal, vol. 45, no. 8, pp. 2428-2433, 2009.

[9] J. W. Park and S. S. Im, "Phase behavior and morphology in blends of poly(L-lactic acid) and poly(butylene succinate)," Journal of Applied Polymer Science, vol. 86, no. 3, pp. 647-655, 2002.

[10] M. E. Broz, D. L. VanderHart, and N. R. Washburn, "Structure and mechanical properties of poly(D,L-lactic acid)/poly $(\varepsilon$ caprolactone) blends," Biomaterials, vol. 24, no. 23, pp. 41814190, 2003.

[11] L. Jiang, M. P. Wolcott, and J. Zhang, "Study of biodegradable polylactide/poly(butylene adipate-co-terephthalate) blends," Biomacromolecules, vol. 7, no. 1, pp. 199-207, 2006.

[12] N. López-Rodríguez, A. López-Arraiza, E. Meaurio, and J. R. Sarasua, "Crystallization, morphology, and mechanical behavior of polylactide/poly( $\varepsilon$-caprolactone) blends," Polymer Engineering \& Science, vol. 46, no. 9, pp. 1299-1308, 2006.

[13] D. Wu, Y. Zhang, L. Yuan, M. Zhang, and W. Zhou, "Viscoelastic interfacial properties of compatibilized poly $(\varepsilon$ - caprolactone)/polylactide blend," Journal of Polymer Science B: Polymer Physics, vol. 48, no. 7, pp. 756-765, 2010.

[14] J.-T. Yeh, C.-J. Wu, C.-H. Tsou et al., "Study on the crystallization, miscibility, morphology, properties of poly(lactic acid)/poly(E-caprolactone) blends," Polymer-Plastics Technology and Engineering, vol. 48, no. 6, pp. 571-578, 2009.

[15] M. Harada, T. Ohya, K. Iida, H. Hayashi, K. Hirano, and H. Fukuda, "Increased impact strength of biodegradable poly(lactic acid)/poly(butylene succinate) blend composites by using isocyanate as a reactive processing agent," Journal of Applied Polymer Science, vol. 106, no. 3, pp. 1813-1820, 2007.

[16] N. Zhang, Q. Wang, J. Ren, and L. Wang, "Preparation and properties of biodegradable poly(lactic acid)/poly(butylene adipateco-terephthalate) blend with glycidyl methacrylate as reactive processing agent," Journal of Materials Science, vol. 44, no. 1, pp. 250-256, 2009.

[17] T. Xu, Z. Tang, and J. Zhu, "Synthesis of polylactide-graftglycidyl methacrylate graft copolymer and its application as a coupling agent in polylactide/bamboo flour biocomposites," Journal of Applied Polymer Science, vol. 125, pp. E622-E627, 2012.

[18] H.-T. Liao and C.-S. Wu, "Preparation and characterization of ternary blends composed of polylactide, poly( $\varepsilon$-caprolactone) and starch," Materials Science and Engineering A, vol. 515, no. 1-2, pp. 207-214, 2009.

[19] Y. F. Kim, C. N. Choi, Y. D. Kim, K. Y. Lee, and M. S. Lee, "Compatibilization of immiscible poly(l-lactide) and low density polyethylene blends," Fibers and Polymers, vol. 5, no. 4, pp. 270-274, 2004. 

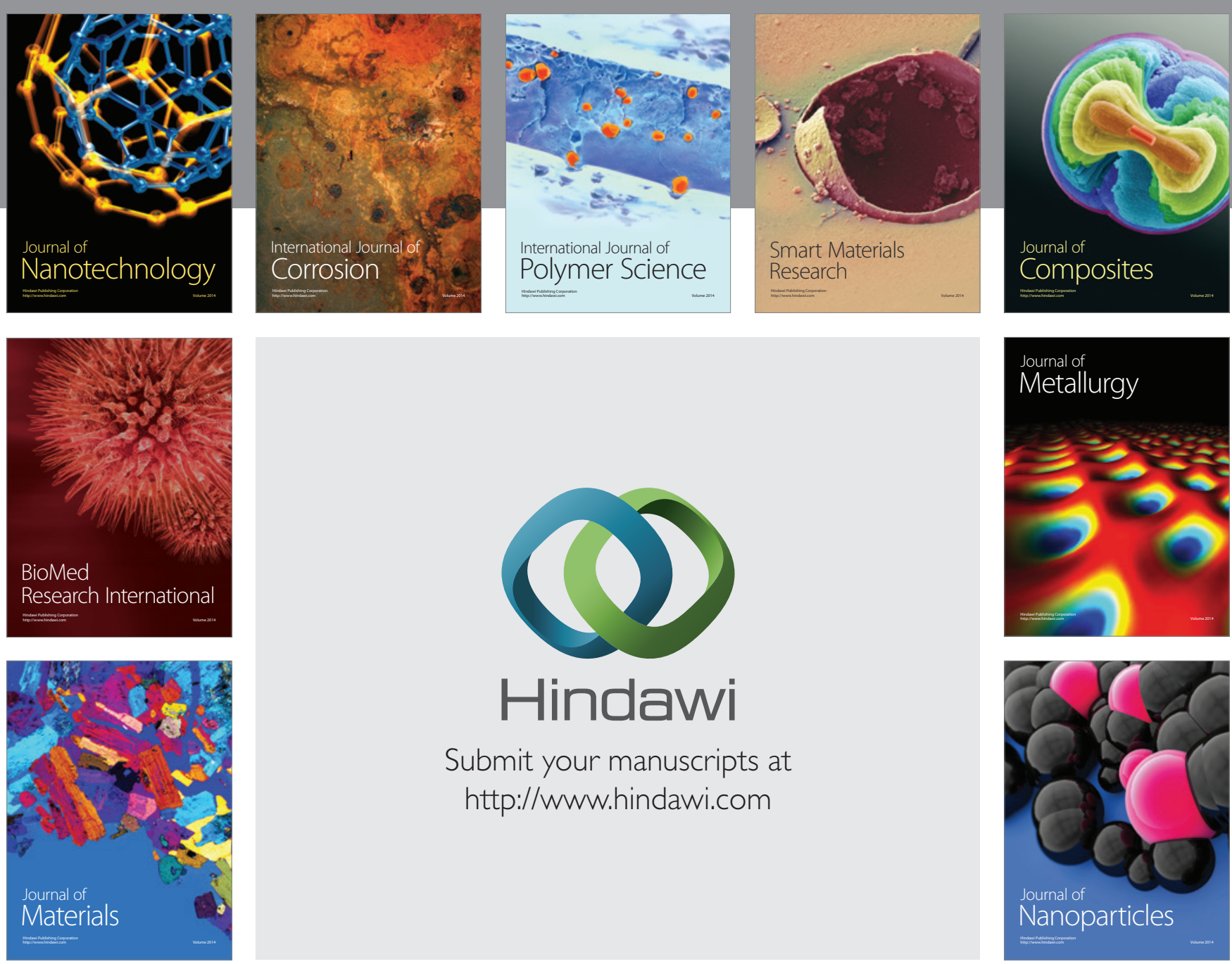

Submit your manuscripts at http://www.hindawi.com
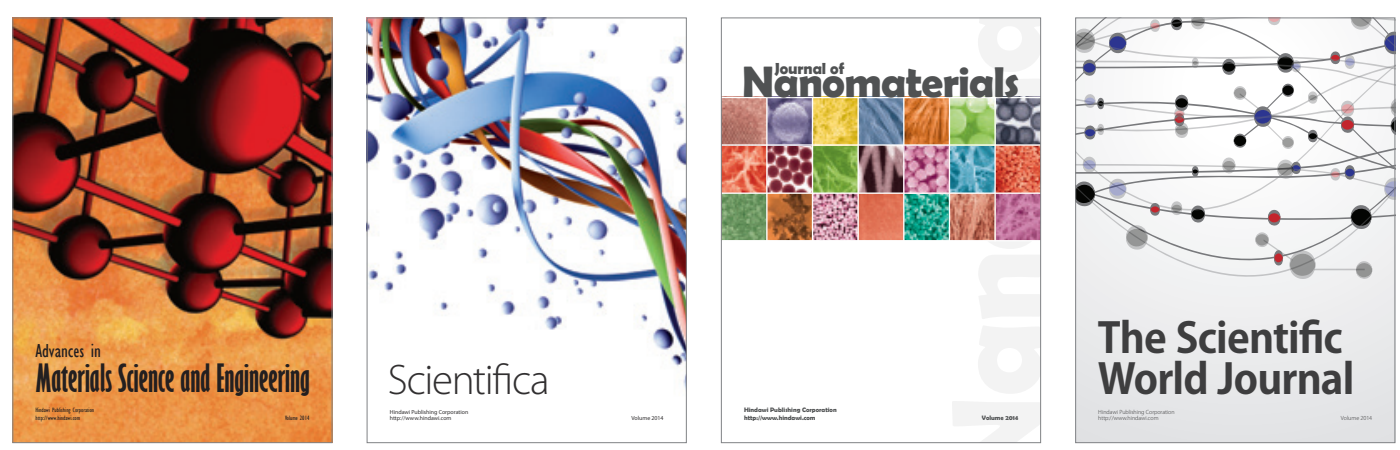

\section{The Scientific World Journal}
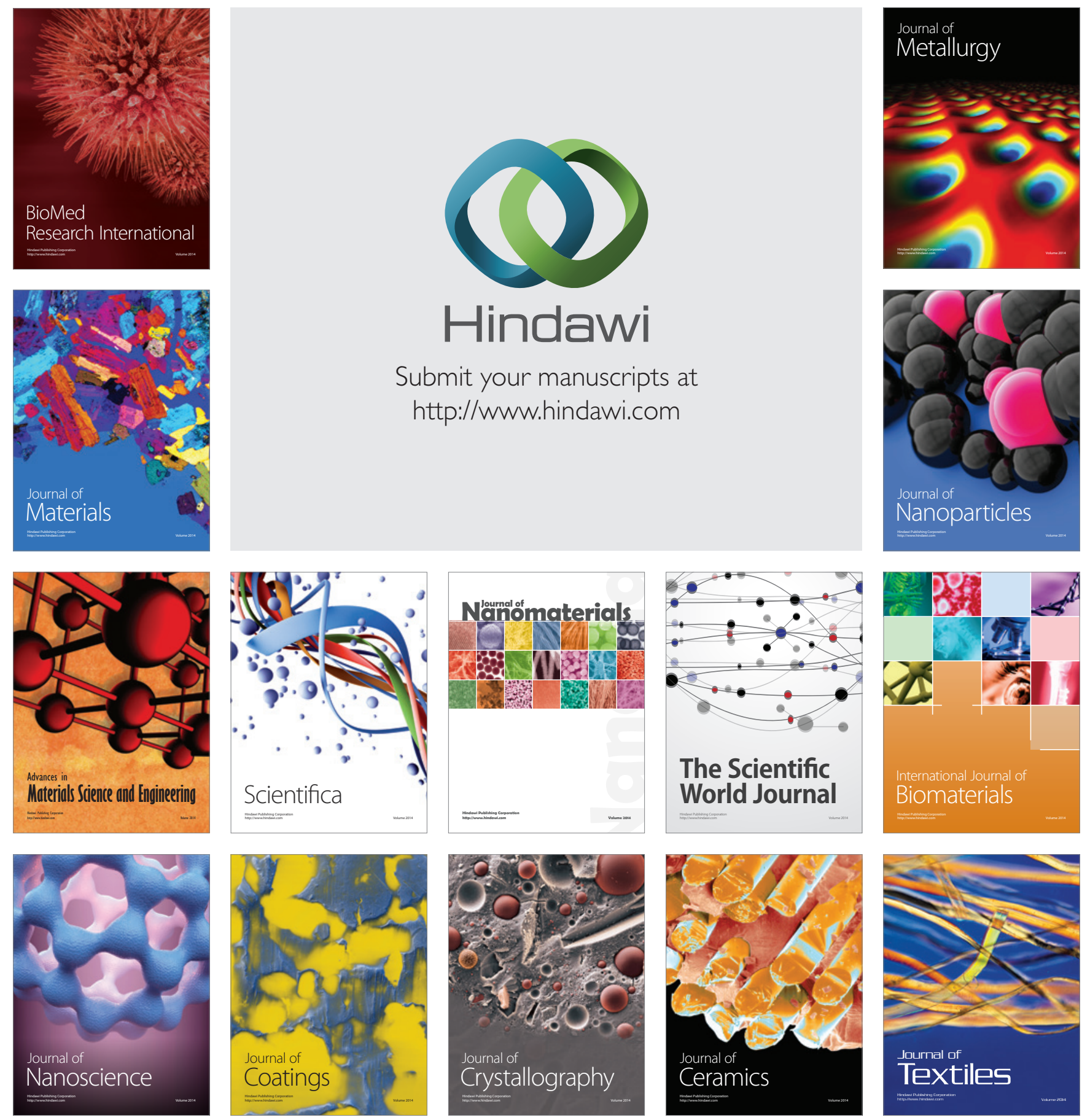